archives

of thermodynamics

Vol. 36(2015), No. 1, 55-65

DOI: $10.1515 /$ aoter-2015-0004

\title{
Influence of nuclear power unit on decreasing emissions of greenhouse gases
}

\author{
WOJCIECH STANEK ${ }^{a 1}$ \\ JAN SZARGUT ${ }^{a}$ \\ ZYGMUNT KOLENDA $^{b}$ \\ LUCYNA CZARNOWSKA ${ }^{a}$
}

a Silesian University of Technology, Institute of Thermal Technology, Konarskiego 22, 44-100 Gliwice, Poland

${ }^{b}$ AGH - University of Science and Technology, Department of Fundamental Research in Energy Engineering, Mickiewicza 30, 30-059 Kraków, Poland

\begin{abstract}
The paper presents a comparison of selected power technologies from the point of view of emissions of greenhouse gases. Such evaluation is most often based only on analysis of direct emissions from combustion. However, the direct analysis does not show full picture of the problem as significant emissions of GHG appear also in the process of mining and transportation of fuel. It is demonstrated in the paper that comparison of power technologies from the GHG point of view has to be done using the cumulative calculus covering the whole cycle of fuel mining, processing, transportation and end-use. From this point of view coal technologies are in comparable level as gas technologies while nuclear power units are characterised with lowest GHG emissions. Mentioned technologies are compared from the point of view of GHG emissions in full cycle. Specific GHG cumulative emission factors per unit of generated electricity are determined. These factors have been applied to simulation of the influence of introduction of nuclear power units on decrease of GHG emissions in domestic scale. Within the presented simulations the prognosis of domestic power sector development according to the Polish energy policy till 2030 has been taken into account. The profitability of introduction of nuclear power units from the point of view of decreasing GHG emissions has been proved.
\end{abstract}

\footnotetext{
${ }^{1}$ Corresponding Author. E-mail: wojciech.stanek@polsl.pl
} 
Keywords: Power plants; Energy policy; Global warming; Greenhouse gasses; Nuclear power

\section{List of abbreviation}

\begin{tabular}{|c|c|c|}
\hline BAT & - & best available techniques \\
\hline GHG & - & greenhouse gasses \\
\hline LCA & - & life cycle assessment \\
\hline NGCC & - & natural gas combined cycle \\
\hline PCI & - & pulverized coal power plant \\
\hline TEC & - & thermo-ecological cost \\
\hline
\end{tabular}

\section{Introduction}

Continuous aspirations for further global economic growth accelerate the consumption of finished stock of nonrenewable resources. Power sector plays a significant role in this consumption, as the electricity is one of the most important energy carriers for many manufacturing processes. Simultaneously, it is responsible for rejection of harmful wastes and greenhouse gasses (GHG) to the nature. It should be pointed out that from the point of view of the whole cycle of resources management from the cradle to grave (i.e., from raw material extraction, materials processing, manufacture, distribution, use, maintenance and disposal or recycling) the nuclear power chain is found as low efficient when comparing with other power technologies fed with nonrenewable primary energy $[1,2]$. However, on the other hand the reported accessible stock of resources of nuclear energy is much more abundant as that of fossil fuels. According to [2,3], the identified resources of uranium that could be extracted at the economic profitability amounts to 5.47 million of ton. This represents a total exergy equal about $0.44 \times 10^{12}$ TJ. For the installed presently power of nuclear power plants the lifetime of identified uranium resources is about 800 years. Besides the identified resources of uranium due to [3] there are also not discovered and unconventional resources of nuclear energy. The total amount of nuclear resources could reach the level of $3 \times 10^{14} \mathrm{TJ}$, which consequently could ensure the enormous long $R / P$ lifetime, namely the reserve-to-production ratio. The information about resources $(R)$, production $(P)$ and lifetime $(R / P)$ of primary energy can be found, e.g., in [2-4]. The $(R / P)$ ratio in the case of fossil fuels is significantly limited [4]: natural gas -56 years, oil -53 years. In the case of coal, during the last decade an extremely rapid decrease of $R / P$ ratio has been observed. The $R / P$ ratio for coal 
in the year 2000 was estimated [4] at the level of 220 years, whereas after 12 years - in 2012, it was estimated only at the level of 109 years. In the face of these arguments, it is probable that the power sector will have to use more nuclear resources. Additionally, the nuclear chain is less responsible for the GHG emissions, as the electricity generation does not include the combustion process. So, the nuclear technology is an interesting option for conventional power plants, because of two facts:

- relatively short lifetime of conventional primary energy resources, and long lifetime of nuclear resources,

- large amount of GHG emissions burdening fossil fuels combustion, and very small GHG emissions burdening nuclear chain.

According to Polish energy policy till 2030 installation of three nuclear power units should be installed. The total power equal to $4.8 \mathrm{GW}$ in these units is expected. The influence of these investments on the structure of electricity generation is presented in Fig. 1.

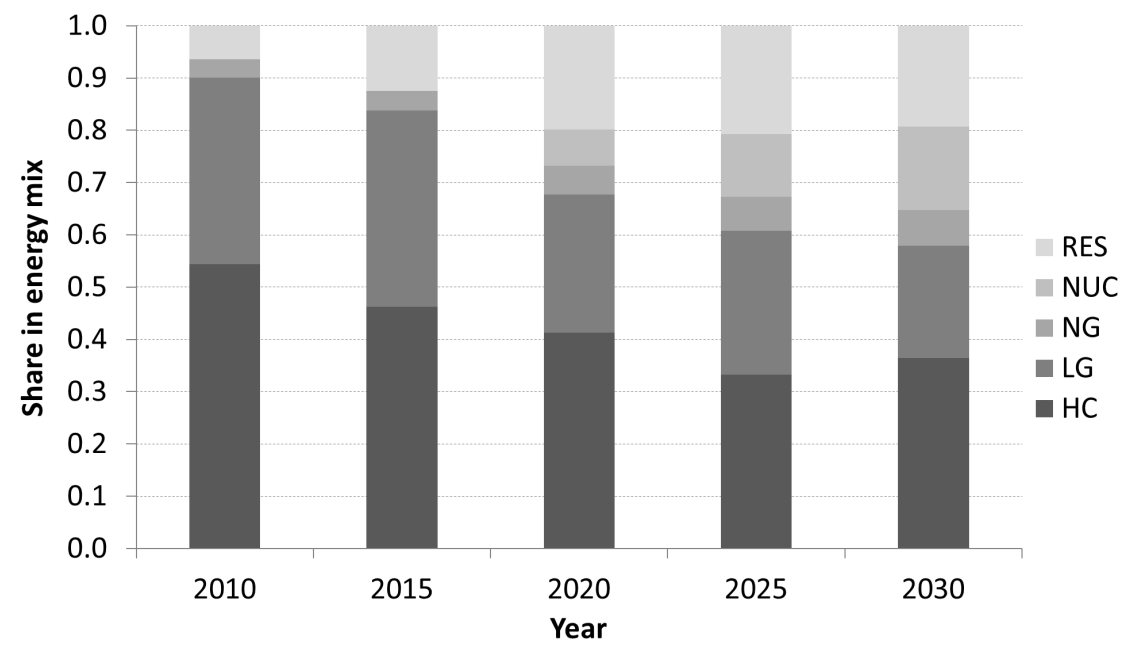

Figure 1: Structure of Polish energy mix according to Polish energy policy (based on [5]); $\mathrm{HC}$ - hard coal; LG - lignite, NG - natural gas; NUC - nuclear energy, RES - renewable energy sources.

The planned changes in the power generation structure should lead to significant decrease of GHG emissions burdening the electricity generation. To analyse the potential in GHG decrease the analysis of cumulative $\mathrm{CO}_{2}$ emissions in the whole cycle has been applied. The comparison with coal and 
gas technology is additionally included. Calculations of emissions within the whole cycle of the plant requires introduction of the data covering not only the operation phase but also other stages such as construction or dismantling. To take into account these stages for analysed power plants the detailed life cycle analysis (LCA) data has been applied $[8,12,13]$ on material consumption. Moreover the authors take into account not only the direct emissions burdening, e.g., fuel consumption but also the emissions covering the extraction and transportation of fuels $[10,15]$. It is especially important to take into account the natural gas transportation that is connected with the methane leakages.

\section{Characteristics of the analysed systems}

The basic factor deciding about the consumption of fuel and furthermore on emissions of waste products is energy efficiency or exergy efficiency. It has been assumed that the average net energy efficiency of coal power plant (PCI) amounts to $\eta_{E, P C}=40.0 \%$. The assumed value is close to the average efficiency of electricity generation in Polish energy system [6]. The best available PCI's plant energy efficiency is approaching at present $50 \%$. The net energy efficiency of best available technology (BAT), natural gas combined cycle (NGCC) gas and steam power plants fired with natural gas is approaching the level of $\eta_{E, C C}=60.0 \%$. For the assumed energy efficiencies the exergy efficiency is: $\eta_{B, P C}=36.7 \%$ and $\eta_{B, C C}=57.7 \%$. The nuclear power plants are most often characterised by the energy efficiency of their thermodynamic cycle. This is by far not enough to compare with other power plants because these parameters characterise only a part of the process of electricity generation. The balance boundary has to be assumed at the fuel delivery to nuclear reactor. It can be made applying the so-called burn-up ratio coefficient, $W_{F}$, expressed usually in $\mathrm{GWd} / \mathrm{tU}$ and calculated as thermal output of reactor, $Q_{t h}$, related to mass of nuclear fuel delivered to the reactor $m_{F}$ [7].

Combining the energy efficiency (thermal efficiency) of the nuclear plant defined as a ratio of generated electricity to the rate of heat delivered to steam cycle $\eta_{t h}=N_{e l} / Q_{t h}$ together with the burn-up ratio $W_{F}$ the energy and exergy efficiency of nuclear power plant can be calculated [1]. The results of calculations of exergy efficiency and system exergy efficiency for compared power technologies are summarised after [1] in Tab. 1.

It is evident that among considered power technologies natural gas 
Influence of nuclear power unit on decreasing. . .

Table 1: Local and system exergy efficiency of compared power technologies.

\begin{tabular}{|l|c|c|}
\hline Power plant & $\begin{array}{c}\text { Local exergy efficiency } \\
\eta_{B, e l}, \%\end{array}$ & $\begin{array}{c}\text { System exergy efficiency } \\
\eta *_{B, e l}, \%\end{array}$ \\
\hline \hline Nuclear existing & 24.1 & 1.71 \\
\hline Nuclear Gen III + & 41.3 & 2.93 \\
\hline Coal average in Poland & 36.7 & 34.83 \\
\hline Coal BAT & 45.9 & 43.48 \\
\hline NGCC (BAT) & 57.7 & 56.18 \\
\hline
\end{tabular}

* average value for reactors existing in 2009: 69 PWR (66\%) and 35 BWR (34\%) [8]

NGCC plant is characterised by the highest exergetic efficiencies. The existing nuclear technologies are characterised by lower of about $10 \mathrm{pp}$ local exergetic efficiencies than assumed coal technology. However, in the case of nuclear power plant the energy or exergy efficiency is not a deciding factor on $\mathrm{CO}_{2}$ emissions because of combustion process absence. In this case it is necessary to consider a full life cycle from the cradle to grave [9-11] by means of system exergy efficiency. Moreover, $\mathrm{CO}_{2}$ emissions have to be compared from the point of view of full cycle. According to Tab. 1 the system exergy efficiency (including full cycle) of electricity generated in existing nuclear technologies is almost 20 times lower than that of existing coal technologies and almost 33 times lower than in case of best available NGCC technology. The introduction of nuclear Gen III + technology [8] should improve the exergy efficiency by 1.7 times. On the other hand the nuclear technologies do not use the combustion process. For this reason they can be more profitable from the point of view of GHG emissions. However, the exergy losses in nuclear chain are mainly located in the production chain of fuel the comparison has to be based on the cumulative emissions with the inclusion of LCA. According to [12] and [13] the influence of the primary energy consumption on the results of total life cycle analysis of PCI and NGCC is about $97 \%$. In [14] the primary energy part of the coal power plant thermo-ecological cost cycle has been estimated at the level of $91 \%$. It can be concluded that the emissions of GHG is mainly due to operational phase of these power plants. For this reasons, the construction material part of life cycle for coal and natural gas power plant has been simplified to the major materials, as presented in Tab. 2 . 
Table 2: Plant construction material requirements, (kg/MW plant capacity) $[12,13]$.

\begin{tabular}{|c|c|c|c|}
\hline No. & Construction material & Coal & Natural gas \\
\hline \hline 1 & Concrete & 158758.0 & 97749.0 \\
\hline 2 & Steel & 50721.0 & 31030.0 \\
\hline 3 & Aluminium & 419.0 & 204.0 \\
\hline 4 & Iron & 619.0 & 408.0 \\
\hline
\end{tabular}

The evaluation of GHG emissions from assumed nuclear power technologies has been determined taking into account the following stages from the cradle to grave: 1) mining and milling of uranium ore (open pit and underground), 2) conversion of $\mathrm{U}_{3} \mathrm{O}_{8}$ into $\mathrm{UF}_{6}$ for the enrichment process, 3) enrichment of nuclear fuel (centrifuge and diffusion), 4) fuel fabrication in the form of $\mathrm{UO}_{2}, 5$ ) fuel transportation, 6) power generation, 7) depleted fuel management. The detailed scheme of this cycle is presented in Fig 2.

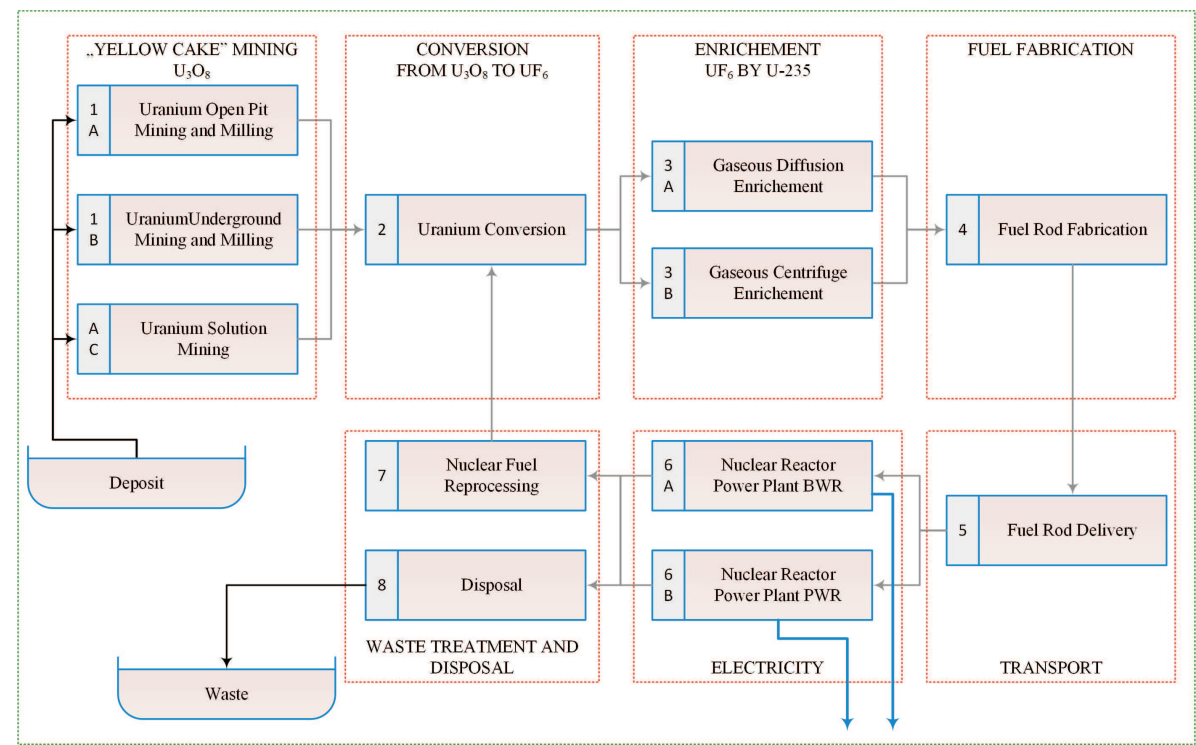

Figure 2: The whole cycle of nuclear technology. 


\section{Cumulative GHG $\left(\mathrm{CO}_{2 e}\right)$ emissions}

The anthropogenic $\mathrm{CO}_{2}$ emission is closely related with the energy efficiency of the transformation of primary fuels, and carbon element content in fuel. Direct emission of $\mathrm{CO}_{2}$ resulting from carbon containing fuels per unit of chemical energy can be readily evaluated using a simple relationship:

$$
\varepsilon_{F}=n_{C}^{\prime} \frac{M_{C O 2}}{(L H V)},
$$

where: $n_{C}^{\prime}$ - fraction of carbon element in the fuel in $\mathrm{kmol} \mathrm{C} / \mathrm{kg}$ fuel or in $\mathrm{kmol} \mathrm{C} / \mathrm{kmol}$ fuel, $M_{C O 2}$ - molar mass of $\mathrm{CO}_{2}$ in $\mathrm{kg} / \mathrm{kmol},(L H V)$ lower heating value of the fuel in $\mathrm{MJ} / \mathrm{kg}$ or $\mathrm{MJ} / \mathrm{kmol}$. In the case of fuel characterised by mass concentration of carbon element $c-n_{C}^{\prime}=c / 12$.

However, the process of mining, processing and delivery of fuel can be also burdened with significant GHG emissions. For example there are methane emission form coal mines or leakages from natural gas transportation pipelines. Inclusion of these impacts can radically change the picture. For this reason to complete evaluation of different energy sources on GHG emissions a cumulative calculus has to be applied. Such balance in the case of greenhouse gasses emissions takes the following form $[10,15]$ :

$$
e_{j}^{*}=\sum_{i}\left(a_{i j}-f_{i j}\right) e_{i}^{*}+\sum_{k}(G W P)_{k} e_{k j}
$$

where:

$e_{j}^{*} \quad-\quad$ cumulative emission of greenhouse gasses in $j$ th production branch,

$a_{i j} \quad-$ coefficient of consumption of $i$ th product in $j$ th branch,

$f_{i j} \quad-$ coefficient of by-production of $i$ th useful product in $j$ th branch,

$e_{i}^{*} \quad-\quad$ coefficient of cumulative emission of greenhouse gasses burdening $i$ th useful product,

$(G W P)_{k}-$ coefficient of global warming potential of $k$ th gas,

$e_{k j} \quad-$ coefficient of direct emission of $k$ th greenhouse gas in $j$ th production branch.

Furthermore, basing on the results of calculations of cumulative emissions by means of Eq. (2) the life cycle emissions (LCE) can be determined. In such case the total LCE burdening the fabrication of considered useful 
product can be determined by means of the following formula $[10,15]$

$$
(\mathrm{LCE})=\tau_{n} \sum_{j} \dot{G}_{j} e_{j}^{*}+\frac{1}{\tau}\left[\sum_{m} G_{m} e_{m}^{*}\left(1-u_{m}\right)+\sum_{r} G_{r} e_{r}^{*}\right],
$$

where:

$\dot{G}_{j}, e_{j}^{*} \quad-$ nominal flow rate of the $j$ th major product and cumulative GHG emission burdening this product,

$\tau_{n} \quad-$ annual operation time with a nominal capacity,

$\tau \quad-$ nominal lifetime of the installation,

$u_{m} \quad-$ expected recovery factor of the $m$ th material,

$G_{m} e_{m}^{*} \quad-\quad$ consumption of $m$ th material or energy carrier used for construction of the installation and cumulative GHG emission burdening the $m$ th product,

$G_{r}, e_{r}^{*} \quad-$ expected consumption of $r$ th material or energy carrier for repairs of the installation and cumulative GHG emission burdening the $r$ th product.

Emissions of GHG in full cycle by means of Eqs. (2) and (3) has been analyzed by Stanek and Białecki in [15]. Table 3 presents the comparison of direct and LCA GHG emissions for coal and natural gas imported from Siberia.

Table 3: Comparison of direct and cumulative emissions of fuels [15].

\begin{tabular}{|c|l|c|c|}
\hline No. & \multicolumn{1}{|c|}{ Fuel } & $\begin{array}{c}\text { Direct } \\
\text { emission } \mathrm{CO}_{2} / \mathrm{TJ}\end{array}$ & $\begin{array}{c}\text { Cumulative } \\
\text { emission } \mathrm{CO}_{2 e} / \mathrm{TJ}\end{array}$ \\
\hline \hline 1 & Coal & 92.0 & 95.8 \\
\hline 2 & Coal (with methane leakage) & 92.0 & $101.6-104.8$ \\
\hline 3 & $\begin{array}{l}\text { Natural gas }(\mathrm{GWP}=30,4.2 \% \\
\text { leak.) }\end{array}$ & 56.0 & 96.9 \\
\hline
\end{tabular}

GUP - global warming potential

The necessity of application of cumulative emissions calculus in the case of GHG is evident. The direct emission of $\mathrm{CO}_{2}$ is 1.6 times higher for coal than for natural gas. The cumulative ratio could only be at the level of 1.05-1.08. In other words the GHG emissions burdening hard coal is quite similar to that of natural gas transported from huge distances. The methodology of life cycle emissions (Eqs. (2) and (3)) and results from Tab. 3 have been used for a comparative analysis of coal, natural gas and nuclear 
power plant analysed previously by means of TEC [1]. The obtained results are summarised in Tab. 4.

Table 4: Comparison of direct and cumulative emissions for power technologies.

\begin{tabular}{|c|l|c|c|}
\hline No. & \multicolumn{1}{|c|}{ Technology } & $\begin{array}{c}\text { Direct emission } \\
\mathrm{t} \mathrm{CO}_{2} / \mathrm{TJ}_{e l}\end{array}$ & $\begin{array}{c}\mathrm{LCA} \text { emission } \\
\mathrm{tCO}_{2 e} / \mathrm{TJ}_{e l}\end{array}$ \\
\hline \hline 1 & Coal average & 230.0 & 254.0 \\
\hline 2 & Coal BAT & 184.0 & 203.0 \\
\hline 3 & NGCC & 93.0 & 161.3 \\
\hline 4 & Nuclear existing & $\mathrm{N} / \mathrm{A}$ & 12.0 \\
\hline 5 & Nuclear Gen III + & $\mathrm{N} / \mathrm{A}$ & 7.0 \\
\hline
\end{tabular}

Direct $\mathrm{CO}_{2}$ is about 2.5 times higher in the case of existing coal technologies than that of NGCC. It is the result of difference in energy efficiency and emission calculated by means of simple stochiometric calculations with of Eq. (1). When cumulative life cycle emissions are compared the gas technology is only 1.5 times better. It proved that evaluation of production chains has to be made by the method of cumulative GHG. The presented results shown additionally that however the system exergy efficiency and TEC is extremely disadvantageous in the case of nuclear technology the GHG emission burdening the whole cycle is negligible in comparison with power technologies fed with chemical primary energy. Both - results of TEC and cumulative GHG analyses could have significant influence on the sustainable exergetic factor and cumulative GHG emissions of Polish energy mix. The introduction of nuclear technologies as planned in Polish energy policy [5] can be competitive for decreasing $\mathrm{CO} 2$ emissions in comparison with other method applied in conventional power technologies as carbon capture [16] or oxy-combustion [17].

\section{Final remarks and conclusions}

The results of GHG emission analysis have been introduced to the prognosis of Polish energy mix presented in Fig. 1. The results of cumulative GHG analysis in respect to the prognosis of Polish energy mix is presented in Fig. 3. The presented results show evidently that however the system exergy efficiency and TEC is extremely disadvantageous in the case of nuclear technology for the planned share of nuclear energy in 2030 of about $15 \%$ 


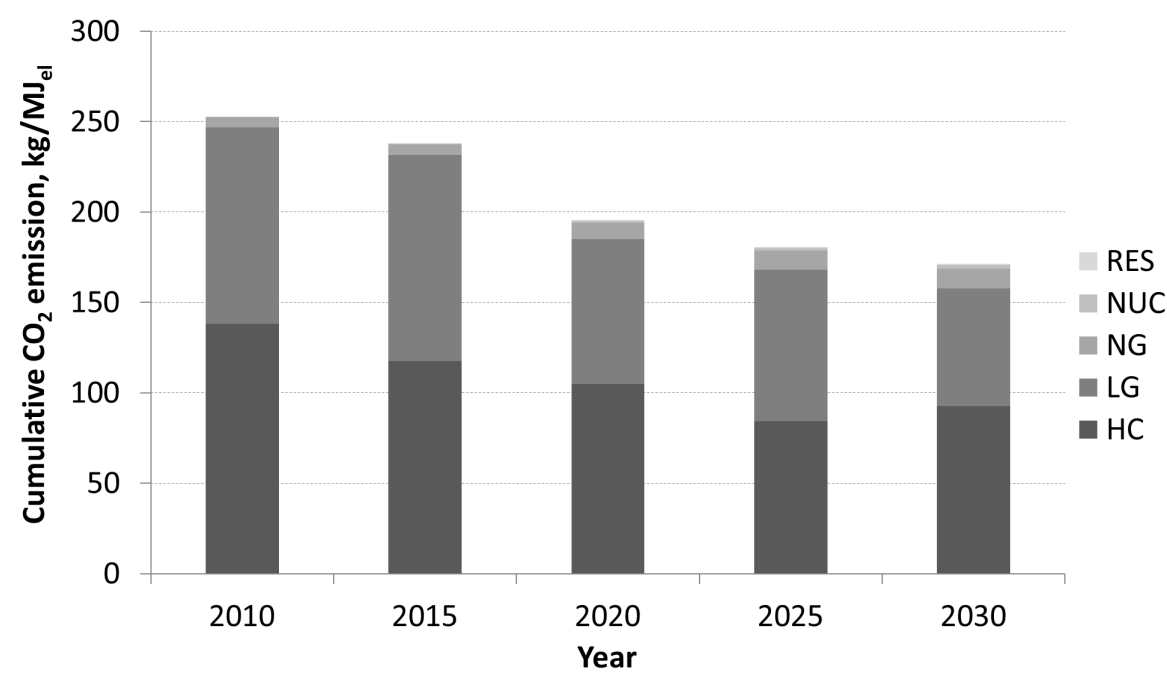

Figure 3: GHG cumulative emissions for planned Polish energy mix (HC - hard coal; LG - lignite, NG - natural gas; NUC - nuclear energy, RES - renewable energy sources).

the GHG burdening the energy mix will be significantly decreasing up to the level of $171 \mathrm{~kg} \mathrm{CO} 2 e / \mathrm{TJ}_{e l}$ in 2030. It means the decrease of more than $30 \%$ in relation to current (year 2010) energy mix based mainly on coal.

Acknowledgments This work has been developed thanks to the support from the statutory research fund of the Faculty of Power and Environmental Engineering of Silesian University of Technology.

This work was also supported by the National Centre for Research and Development (Project HTRPL, Contract No. SP/J/1/166183/12).

Received 10 December 2014

\section{References}

[1] Stanek W., Szargut J., Kolenda Z., Czarnowska L., Bury T.: Thermoecological evaluation of nuclear power plant within the whole life cycle. In: Proc. Conf. ECOS'2014. Turku 2014.

[2] Tani F., Haldi P-A., Favrat D.: Exergy-based comparison of the nuclear fuel cycles of light water and generation IV reactors. In: Proc. Conf. ECOS 2010, Lausanne 2010. 
[3] Hermann W.: Quantifying global exergy resources. Energy 31(2006), 1685-1702.

[4] Statistical Review of World Energy 2013. www.bp.com (last accessed Jan. 2014).

[5] Energy Policy of Poland for 2030. Ministry of Economy 2009. www.mg.gov.pl (last accessed Sept. 2014.

[6] Energy and fuel management in 2011, 2012. GUS, (in Polish). www.stat.gov.pl (last accessed Sept. 2014) .

[7] Celinski Z., Strupczewski A.: Nuclear Power. WNT, Warszawa 1984 (in Polish).

[8] Role of Alternative Energy Sources: Nuclear Technology Assessment. DOE/ NETL-2011/1502. August 8, 2012. National Energy Technology Laboratory. www.netl.doe.gov (last accessed 23.01.2014.

[9] Szargut J., ZięBiK A., StaneK W.: Depletion of the non-renewable natural exergy resources as a measure of the ecological cost. Energ. Convers. Manage. 42(2002), $1149-1163$.

[10] Szargut J., Stanek W.: Thermo-climatic cost of the domestic consumption products. Energy 35(2010), 2, 1196-1199.

[11] Finneveden G., Ostlund P.: Exergies of natural resources in life-cycle assessment and other applications. Energy 22(1997), 9.

[12] Life Cycle Analysis: Existing Pulverized Coal (EXPC) Power Plant. DOE/NETL403-110809. September 30, 2010. National Energy Technology Laboratory. www.netl.doe.gov (last accessed Sept. 2014).

[13] Life Cycle Analysis: Natural Gas Combined Cycle (NGCC) Power Plant. DOE/ NETL-403-110509. September 30, 2010. National Energy Technology Laboratory. www.netl.doe.gov (last accessed Sept. 2014).

[14] StaneK W.: Method of evaluation of ecological effects in thermal processes with the application of exergy analysis. Silesian University of Technology Press, Gliwice 2009 (in Polish).

[15] Stanek W., Bialecki R.: Can natural gas warm the climate more than coal? Fuel 136 (2014), 341-348.

[16] Kotowicz J., Dryjańska A.: Supercritical power plant $600 \mathrm{MW}$ with cryogenic oxygen plant and CCS installation. Arch. Thermodyn. 34(2013), 3, 123-137.

[17] ZIĘBIK A., Geadysz P.: Analysis of the cumulative exergy consumption of an integrated oxy-fuel combustion power plant. Arch. Thermodyn. 34(2013), 3, 105122. 